\title{
FROM ADVANCED TOWARDS EFFECTIVE TRAVELLER INFORMATION SYSTEMS
}

\author{
Glenn D. Lyons \\ Transportation Research Group, University of Southampton, UK
}

\section{INTRODUCTION}

Travellers face a number of choices both before and during a trip including when to travel, where to travel, which mode to use, which route to use or even whether or not to make the trip at all. Individuals consider the available alternative choices and based on their understanding or perception of the relative merits of each alternative determine the preferred way to execute the trip. If an individual was fully aware of all available and viable alternatives for each choice decision and had a complete and accurate knowledge concerning those alternatives then rationally he or she would be able to identify the alternatives that would minimise the cost or disutility of making the trip. Cost is not only financial. Generalised travel cost is a measure combining all the attributes of cost to the individual including travel time, monetary cost, security, comfort, convenience and reliability (Ortúzar and Willumsen, 1994). Each individual perceives and weighs each element of cost differently. Individuals seldom possess complete and perfect knowledge concerning their travel choices. There may be a lack of awareness of available alternatives. There may be an incomplete knowledge of values associated with generalised travel cost elements. Knowledge of such values may be out of date and inaccurate or the values may change on a day to day basis. Incomplete or dated knowledge can become coloured by past experience and perceptions. Such shortcomings can conspire to result in travel choices and experiences that are sub-optimal both for the individual traveller and the transportation system as a whole.

Information has the potential to address the issue of incomplete or imperfect knowledge. Information empowers the traveller enabling potentially better choices to be made. The provision of information to travellers to assist in choice making is not a new concept although the sophistication and scope of its provision has increased considerably. Information delivered without the aid of information and communications technology (ICT) has existed for many years. Road maps enable alternative routes to be compared in terms of distance and indications of road types can allow the user to crudely estimate likely travel times for such routes. Road signs offer drivers regular information updates on directions and distances during a journey. Paper timetables for buses and trains provide information on public transport departure times, journey times and routes.

As the ICT revolution has taken place there has been an emergence of advanced transport telematics (ATT) leading to the concept of intelligent transport systems (ITS) and advanced traveller information systems (ATIS). Information can now be provided to travellers using a variety of media. Radio broadcasts of traffic reports are now widespread. These serve to provide both pre-trip and en-route information and have 
principally informed motorists of incidents and other restrictions on major routes. Notification of any abnormal conditions on public transport services are also included in some broadcasts. The increasing sophistication of radio broadcasting is highlighted by the use of Radio Data System (RDS) Services and the development of RDS-TMC (Traffic Message Channel). The latter promises the possibility of information personalised by locality, route names or even destination of travel (Nuttall, 1995). Variable message signs (VMS) provide a network of dissemination points for real-time information. Drivers can receive route choice information or parking guidance information (PGI) (McDonald et al., 1995) and public transport users are informed of arrival times at stations and bus-stops (Brown, 1994). Telephone enquiry services introduce a human interface to ATIS. The London Transport Travel Information Service with its sophisticated ROUTES system (London Transport, 1997) is a typical example. The service provides passengers with impartial advice about every aspect of travelling around London. Similar computer-based systems also interface with passengers in the form of journey planning terminals located at stations and public amenities (Brown and Ness, 1995). Users are able to submit a query to the system and uni- or multi-modal journey plans are returned. The sophistication of in-car route guidance systems continues to increase with inclusion of realtime information on traffic network conditions. The Internet and World Wide Web (Web) have now become a formidable force in the delivery of pre-trip information for all modes with Web sites providing journey planning facilities for public and private transport and real-time information on traffic flows, speeds and incidents using both text and images.

Adler and Blue (1998) set out the evolution of information systems referring to three generations of (ICTbased) systems:

- traveller information systems (TIS) - first generation systems that arose from the emergence of computer technologies and traffic surveillance and control systems in the late 1960s and 1970s;

- advanced traveller information systems (ATIS) - second generations systems whose growth and maturity is currently being experienced with new technologies being embraced to provide travellers with dynamic route guidance, real-time traffic condition information and traveller services information - such systems enable the amount of information provided to the traveller to be reduced focussing on the specific needs of each traveller; and

- intelligent traveller information systems (ITIS) - third generation systems which it is asserted will offer more personalised and intelligent systems occurring as a result of the integration of Artificial Intelligence with ATIS.

The terminology and phraseology above reflect an evolution of information systems that an observer could be forgiven for assuming is driven by technology and sophisticated computation. The term 'advanced' in most ATIS literature appears strongly associated with 'high-tech' and the ability to deliver real-time information via sophisticated hand-held or in-car devices. This paper makes the contention that a truly advanced traveller information system is not adequately reflected in any of the definitions above and proposes a new systems’ definition, namely effective traveller information systems (ETIS).

Information systems are provided to serve a purpose. From the traveller's perspective an information system is effective if it enables the traveller to execute a trip with a lower generalised travel cost than could have been achieved in its absence. From the system provider's perspective an information system is effective if, for example, it results in higher patronage levels or greater satisfaction from passengers in the case of public transport or better use of routes and road capacity in the case of private travel on the highway network. If a system is not effective then, regardless of its technical sophistication, this paper asserts it cannot truly be advanced. This is not to say that ICT does not play an important part in rendering a system effective, but that technology alone does not guarantee effectiveness.

This paper stems from a UK research study that investigated the user requirements from traveller information systems. The paper highlights a number of factors that are believed to collectively determine 
effectiveness of information provision. Commentary is supported by findings and quotes from a series of focus groups that were conducted to explore the reactions of different groups of travellers to travel and information requirements.

It is apparent from the literature on ATIS, much of which is from the US, that in many cases the term traveller is treated synonymously with the term driver. Hence much research in the field relates to driver information systems and concerns navigation and route choice. Such an emphasis is understandable given the predominance of the car. For example in Southern California over 80 per cent of commuters travel alone via personal vehicles while according to the 1990 US census only five per cent of Californians regularly use public transport (Wells and Horan, 1999). However, there is an increasing recognition in many countries that alternative modes to the car must be promoted in an attempt to arrest the growth in car dependence and car travel that causes an increasing prevalence of congestion on highway networks. As a consequence, greater attention is being paid to developments in public transport information systems. Research is also ongoing concerning the move towards integrated systems delivering truly multi-modal information that can influence travel choice and specifically mode choice (Lyons, 2001). This paper, in exploring the proposition of ETIS, does not infer reference solely to drivers when the term traveller is used. Indeed, while the term is taken in its widest sense to refer to travellers irrespective of mode, the emphasis of the paper is towards public transport usage and information. UK-related material is, on occasion, included reflecting the origins of the research. However, key issues discussed in the paper are not intended or considered to be parochial.

\section{DEFINING THE EFFECTIVENESS OF INFORMATION PROVISION}

This paper defines Effective Traveller Information Systems (ETIS) as: systems that achieve benefits for the traveller and/or the information systems' providers.

\section{Benefits to the Information System Provider}

Those responsible for funding or providing information systems are likely to be seeking one or more of the following benefits:

- Financial - Beyond certain statutory obligations to provide information, private sector public transport service operators will invest in information provision if revenues from ticket sales can be increased. Revenue increases may result from greater use of services by existing public transport users or from new users from other modes. Private sector driver information providers (sometimes referred to as Value Added Service Providers) will be seeking profit through the sale of devices used to access their information and/or through payment to access the information either on a subscription basis or pay-peruse basis. Web-based information services with very high usage levels may also derive a financial return through the use of advertising banners on their sites.

- Economic - Congestion and unreliability of journeys add to the costs of business and undermine competitiveness, particularly in urban areas where traffic is worst. The Confederation of British Industry (CBI, 1995) has put the cost of congestion to the British economy at around $£ 15$ billion every year. Central and local government invest in information provision with the aim of encouraging a better distribution of travel demand across time of day, routes and modes such that congestion is reduced (or can be prevented from getting worse). Public authorities managing strategic road networks, have a responsibility to ensure efficient use of such networks for economic reasons as well as maintaining safety standards and attempting to minimise environmental pollution from vehicle emissions. Unlike private sector public transport service providers, such authorities would be pleased to see a reduction in their customer numbers. 
- Environmental - Motor vehicles produce emissions. Emission levels and the consequent degradation in air quality are influenced by the number of vehicles and the emission rate per vehicle. The latter is related to vehicle speed with a sharp increase in emission levels at very low speeds which occur in congested conditions. Hence traffic congestion causes economic and environmental problems both of which can be reduced by reducing congestion. Public authorities through the introduction of international and nationally set targets have a strong motivation to reduce emission levels and will be prepared to invest in information services that can assist in achieving such reductions through influencing travel choices.

- Social - One in three households in the UK does not own a car. A significant proportion of the population are dependent on public transport. Inadequate information provision may diminish the accessibility of public transport particularly in areas where services are infrequent and people are not familiar with when and from where public transport services run. By making public transport more accessible and improving the ability of individuals to plan and execute trips using public transport, social exclusion can be reduced. It must be noted that information alone is not enough to fully address certain matters of accessibility. Ultimately the public transport services themselves must be improved.

\section{Benefits to the Traveller}

The benefit to the traveller in using an information system is an improvement in the ability to plan and execute a journey at a lower 'cost' to the individual. Such a benefit may arise in a number of ways from information provision. Information may determine whether or not a trip is made using a particular mode. It may result in a change in intended mode choice. It can also improve the quality of travel once a particular mode has been selected. Anderson (1993) identified six objectives for a passenger rail information system related to this latter point. These are:

1. to assist passengers in planning and during their journeys;

2. to improve passengers' efficiency of movement through the system (leading to a reduction in travel time, or their perception of it);

3. to provide reassurance and confidence to passengers (indicating that staff know what is happening and are in control);

4. to advise passengers if changes in their route become necessary;

5. to enhance the quality and range of services offered (with the aim of attracting more passengers); and

6. to provide staff with a better picture of what is happening (to enable them to effectively respond to enquiries from passengers).

Many of these points would be equally applicable to motorists. Several points directly or indirectly also relate to benefits to the information systems’ providers.

\section{FACTORS GOVERNING AN EFFECTIVE TRAVELLER INFORMATION SYSTEM}

Some assessments of ATIS might be viewed as too clinical or even superficial. Field trials of ATIS or stated-preference testing might only focus on the reactions of travellers to specific information items in terms of how they affect their choices. Yet there are a number of factors beyond such immediate considerations (which are often those reported on) that conspire to determine the effectiveness or degree of success of the information system. Figure 1 sets out schematically a series of such factors. It depicts a notional sequence of hurdles that must be overcome to achieve effectiveness. Each factor is discussed in turn with the inclusion of statements made by travellers during the series of focus groups. 


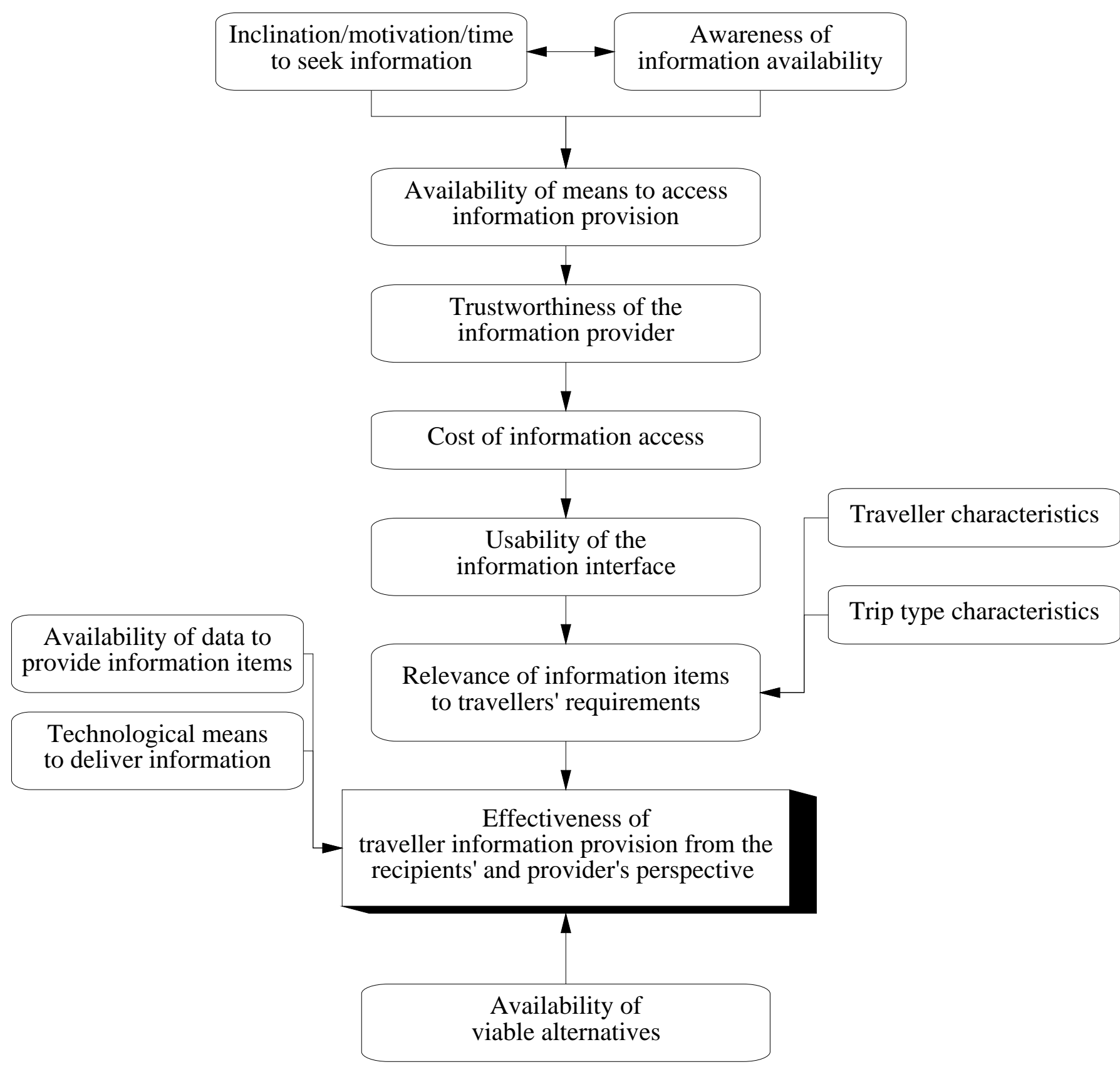

Figure 1. Factors Contributing to the Delivery of ETIS

\section{Inclination/Motivation/Time to Seek Information}

The success or value of an information system is often judged by user reactions to the system. However, the wider interpretation of such reactions and particularly the scales of impact must be set into context by how many individuals in practice would make use of the system. Assessing user reactions and influences on choice presupposes that the system provider has 'got the traveller to the negotiating table'. If an individual does not make use of an information system then such a system cannot be deemed effective (for that individual). The phrase 'cash rich, time poor' reflects the lifestyle of many people in today's society. Seeking information is (perceived to be) a time consuming activity in itself. As such it should perhaps be treated as an element of generalised travel cost. Many people feel they do not have the time or inclination to seek information. They prefer to remain with their existing habits of travel behaviour. Through not seeking information they may reinforce misconceptions about alternatives and are likely to preclude alternative choices, irrespective of the cost of the alternatives: “it doesn't even occur to me to take the bus - I live 
probably a mile from my station I should walk but I always get a cab, but there's a bus garage literally on the corner but I just think that to try and find out is going to be complicated and time consuming". People who are not naturally information seekers are likely in turn to be poor journey planners and make suboptimal choices as a result. Small hurdles to seeking information can be enough to dissuade the exploration of alternatives. While many people are aware of the telephone enquiry lines for public transport information in the UK they cannot remember the telephone number and often lack the inclination to seek it out. Memory of a taxi firm telephone number often appears more forthcoming and offers a low effort (if somewhat higher monetary cost) alternative to considering and planning to use other modes: "It's laziness I think from a lot of people's point of view, it's a lot easier to just phone a taxi”.

Discrete choice theory considers different decision rules (Ben Akiva and Lerman, 1993). The rule commonly related to mode choice concerns utility maximisation. It is assumed that an individual assesses the alternatives and selects that which he or she perceives offers the highest utility (or lowest disutility in the case of travel choices). An alternative rule concerns satisfaction. It is assumed that if an alternative satisfies the minimum requirements of the individual then it may be chosen. This form of choice making, if it prevails in practice, is a disincentive to seeking information. If an individual is already aware of at least one alternative travel choice (or set of choices) that satisfy minimum requirements then there is no motivation to seek information in order to explore further alternatives. Such choice making reinforces habitual behaviour. Familiarity of the individual with particular alternatives improves their confidence in making trips using those alternatives. Unfamiliar choices then inherently have greater generalised travel cost in terms of (mental) comfort or convenience. For example, Wells and Horan (1999) identified commuters' unwillingness to modify routes which they referred to as 'route-choice inertia'.

The need or motivation to seek information from a particular ICT based information system may be removed by the use of alternative human systems. Family, friends, neighbours and colleagues are often cited as useful and trusted sources of information. This is discussed later.

\section{Awareness of Information Availability}

If an individual is unaware that an information source exists then that person is unlikely to be able to make use of it, particularly in the absence of a strong motivation or incentive to seek information. Even if the individual is aware of an information source he or she may not be able to directly make use of it without further effort to determine how to access the system. For example, in the UK many people are aware of the National Rail Enquiry (telephone) Service but are then confronted with the need to find out the telephone number. Awareness of information services can be improved through marketing and advertising. The importance of this is becoming more widely recognised although necessary expenditure is often not forthcoming. Awareness is also improved through word-of-mouth and electronic communication. Lack of awareness remains however. In London focus group sessions many of the participants were unaware of London's ROUTES travel information service for public transport (mentioned earlier). Lack of awareness of information sources can lead to the persistence of a lack of awareness about travel alternatives: "I got really fed up with this, and then two weeks after we'd been doing this [taking children to school using the train/tube during rush hour] I discovered [by chance] there was a bus route that was just across the park from where I lived...it's an empty bus than ran right past the school and took ten minutes".

\section{Available of Means to Access Information Provision}

Some individuals are excluded from certain travel choices by, for example, not owning a car. In a similar way some individuals are excluded from certain information systems, for example by not having access to the Web (there are over 400 public transport information Web sites in the UK (Austin, 1999)). In the context 
of the Web certain sites which use sophisticated Web functionality cannot be used by individuals who only have Web browsers with basic functionality. Information system providers must be aware of sections of society that may be prevented from making use of a service by not having the necessary means of access. Technology both in terms of capabilities and affordability is rapidly increasing the means to access information. 94 per cent of UK households have a telephone. It is estimated that 41 per cent of the population have mobile phones and the number of handsets now outnumbers the 23.8 million residential fixed lines installed nation-wide (McIntosh, 2000). Recent survey results suggest that at the end of 1999 approximately 20 per cent of Britons were using the Internet (Internet Magazine, 1999). As access to information increases the propensity to seek information may also increase.

\section{Trustworthiness of the Information Provider}

The term trustworthiness is perhaps somewhat extreme. However it reflects the need for users to be able to have confidence in approaching and using particular information sources. Confidence may arise if users believe the information providers understand their specific needs or if the information provided is accurate or if it is unbiased. Confidence will also be affected by an individual's familiarity and confidence in making a particular trip. Uncertainty and nervousness about unfamiliar travelling territory can lead to a greater requirement from and need for confidence in information sources and a need, perhaps, to be told what to do. These determinants of confidence are reflected in the use of an information source that can deliver high (even if misplaced) confidence, namely other travellers.

Other travellers are assumed to possess experience of and information about carrying out particular journeys "The information is there if you want it, there's always people at a bus station who know about the bus...elderly people always know about the bus". Some travellers assume that formal information systems and transport systems are designed for the intelligent, able-bodied, affluent and baggage-free travellers and do not seek to accommodate their own needs. For example mothers with young children in London see the transport system and consequently the information services as being designed for the commuter. They do not believe that information is provided to help in travelling with small children "I think they [the information providers] do it [provide information] because they're obliged to do it, not because they actually want to give the information out to make the actual journey better...they're giving you information but its not the information you want to know". As a result they rely on other mothers, family and friends who they believe understand their needs to advise them on how to travel.

Some travellers exhibit their mistrust of information systems, or a need for greater confidence, by taking steps to corroborate the information that is provided. Impartiality in information provision is also important or at least transparency of any influences. Drivers, for example, are wary of the prospect of multi-modal information systems fearing that, if provided or supported by the public sector, they may be supporting an agenda of discouraging car use and will therefore bias information provision in favour of public transport. It is readily apparent is discussion with travellers that they often make a strong association between the transport services and the information services. If both are deemed to have the same source organisation and individuals have a low opinion of the transport services then the information services will be rated accordingly. This can be detrimental to confidence in information systems.

\section{Cost of Information Access}

The monetary cost of acquiring information may dissuade potential users of information systems. Cost of access to information can exist in a number of forms. There may be a cost in terms of the equipment or device required to gain access. Some devices are specific to the information system such as in-car navigation aids while others are for general information exchange, such as mobile phones, and may not be purchased 
with access to traveller information being the primary use. If the cost of information access is subscription based then the user is fully aware of that cost. Pay-per-use may not have its costs perceived in the same way by the end-user. For example to call a telephone enquiry service may involve a free call or a call set at a local, national or premium charging rate. The individual making the call may only recognise any cost in the telephone billing and therefore may perceive the service as free or very low cost in the absence of an 'upfront' payment.

Travellers can understandably give a very negative response to the prospect of payment for information. They perceive the information service in many cases as being part of the transport service for which they are already paying. Reactions depend upon the types of information being considered. Information that relates to problems concerning the transport system such as incidents on the highway network or public transport vehicles not running to schedule is important to travellers. Yet such information reflects failings in the transport system and a reduction in quality of service to the traveller. Travellers are therefore objectionable to having to pay to be told they are getting a second rate service.

The Web offers an overwhelming amount of freely accessible information. As more and more travel information sites emerge there is a growing expectation among travellers that information will be freely available on the Web and if particular information is not yet available it is assumed that it will only be a matter of time before it is. Hence, payment-based information services may discourage potential users because of the points above with reinforcement from preceding factors of (in)effectiveness.

\section{Usability of the Information Interface}

Usability is the first factor concerning the effectiveness of information systems that is directly related to the information system itself. Usability of information systems is a discipline in its own right and cannot be afforded the depth of coverage in this paper it deserves in terms of developing better information systems. Usability is strongly linked to accessibility. If a user has the means to access the information service but is unable to (easily) use the service then it is rendered effectively inaccessible. Usability reflects the ease with which an individual can locate information specific to his or her needs. Poor usability may result in failure to find information or an unacceptable increase in time to acquire information. Telephone enquiry services typically handle a large number of calls and callers can be subject to automated menu-driven call handling. This requires the caller to use the telephone dialling buttons to instruct the system of his or her requirements before being able to speak to a human operative. The frustration caused by such systems is frequently expressed in focus group discussion and reflects a poor perception of usability. In many instances human sources of information are seen as more usable than automated systems. However the reverse can also be true: "Yes, they [computer-based information systems] can't scowl and you can play about and eventually you'll find that it's good". Usability of the information interface will be dependent on the individual user. For example it is widely recognised that Beck's London Underground map is a leading example of good usability, yet many people cannot read maps and find the Underground map confusing. In general good design involves being able to retain simplicity of information access. However, as the volume of information and information enquiry options continues to increase this can become increasingly difficult.

\section{Relevance of Information Items to Travellers’ Requirements}

It cannot be assumed that all travellers are homogeneous in their information requirements. Some information items such as public transport departure times will be of relevance to most if not all travellers seeking information on public transport. Other information items will only be of relevance to sub-sets of travellers. Particular items or types of traveller information might be notionally graded by each traveller into one of the three categories as shown in Table 1. 


\begin{tabular}{||ll||}
\hline Grading & Interpretation \\
\hline Very important & $\begin{array}{l}\text { information that is essential in determining the choice of mode, } \\
\text { route or destination or whether or not to make a trip } \\
\text { information that does not affect the travel choices above but } \\
\text { which enables the traveller to make a more convenient, } \\
\text { Comfortable trip with possibly greater confidence and assurance } \\
\text { information which offers no value to the traveller in either } \\
\end{array} \quad \begin{array}{l}\text { planning or executing a trip and which would be likely to be } \\
\text { viewed as irrelevant or off-putting }\end{array}$ \\
\hline
\end{tabular}

Table 1. Notional Grading of Information Item Importance

If items of information deemed to be very important by a particular traveller are absent from an information system then for that individual the system has exhibited a serious failing in effectiveness which cannot be rectified by the quality of usability. Conversely if an individual is confronted with a bewildering amount of information that he or she deems irrelevant then the usability of the system and hence the effectiveness is also likely to be compromised. Both situations can be addressed if traveller requirements across the target population of users are understood and provided for. Personalisation of information systems is increasingly possible and can be used to provide more convenient access to information.

Information requirements highlight the potentially misplaced emphasis that is sometimes placed on 'advanced' information relating to global positioning, real-time data, forecasting of future traffic conditions etc. This appears in some cases to be done at the expense of considering the potential of 'basic' information that has yet to be fully exploited. For example, for individuals with mobility impairment it is likely to be more important to know whether or not a train station's escalators and lifts are working than to have realtime updates to the nearest minute on when the next train is arriving. The need for basic information does not discredit efforts to provide advanced information but the former in some situations can be decisive in travel choices "Mornington Crescent station before the renovation, the escalators were always broken. If I'd had my kids with me, I'd never get them up the spiral staircase and you can't get them up the escalators". Similarly drivers may value improvements to fixed directional signing on the road network (to reduce the number of 'lost miles' which are travelled) more highly than real-time information concerning incidents and congestion.

Some determinants of travel choice are very much removed from 'advanced' information to the extent that an information system may not be able to have any influence. Travel time, for example, is often assumed to be an element of generalised travel cost that an individual would chose to reduce. This presupposes that journey time is unproductive time. Longer distance public transport journeys in particular offer the prospect of relaxing, sleeping or working during the journey. Such a prospect might be viewed as a positive attribute to the extent that journey times that might be longer than those by car are preferable or even desirable. A traveller may not need an information system to determine the relative merits of using journey time productively when travelling by car or train. However, perhaps basic information concerning levels of crowding on particular trains and hence seating availability to work or even the availability of carriages where mobile phones are banned might provide relevant and valuable information in the context of this particular example.

Information requirements are governed by characteristics of the traveller and trip. Such characteristics also exhibit an influence on other factors determining effectiveness. In order to interpret the influences of traveller and trip characteristics on information requirements care must be taken in defining such characteristics. The term 'business traveller', for example, is misleading. It suggests a characteristic of the traveller when in fact it reflects characteristics of the trip such as punctuality constraints and coverage of 
travel expenses. The requirements of an individual making a business trip are shaped by the nature of the trip but also the nature of the individual in terms of his or her propensity to seek information and the values associated with the different elements of generalised travel cost.

\section{Other Determinants of Effectiveness}

There are addition factors that contribute to the effectiveness of information systems. The availability of information items identified as relevant to travellers' needs requires in turn that data can be collected to support the provision of such items. Data collection, depending on the specific data being acquired, is not an insignificant task and the costs of data collection infrastructure particularly associated with dynamic information can be substantial. Although this paper has emphasised the need to question the implicit assumption that technologically advanced systems equate to advanced or effective traveller information systems, technological requirements are nevertheless another key element of delivering effective systems. Technology facilitates the flow and management of information from the transport systems to the information system and in turn the end user. The use of two-way information flow between the user and the information system is also increasingly common as a result of technological advancements.

The remaining determinant of effectiveness is outside the control of the information system provider. Particularly in cases where information is provided to influence and change travel decisions, there has to be an availability of viable alternatives. Information can change perceptions of generalised travel cost but it cannot usually change the actual cost (although by, for example, making a public transport journey easier to interpret and execute, cost in terms of (mental) comfort may be influenced). So, for example, a multi-modal information system that seeks to encourage drivers to switch to public transport may only serve to highlight that, in terms of generalised travel cost, public transport is more expensive than travelling by car and thereby reinforce a decision to use the car.

\section{CONCLUDING REMARKS}

The primary aim of this paper has been to introduce a new information systems' definition, namely Effective Traveller Information Systems. In so doing, the importance of adopting an holistic approach to the effective delivery of information has been highlighted. New technologies are facilitating much greater availability of and access to information. Data management techniques now allow vast and complex databases to be interrogated by users with relative ease. These are important advances, but advances which in themselves do not guarantee that the provision of information will result in positive effects and benefits to either the traveller or those responsible for funding or providing information systems. There are many human factors to be considered that relate to whether individuals can or will seek, access and act upon information that is available. In terms of managing travel demand and making efficient use of transport networks it is not sufficient to only assess the quality of an information system itself. It is necessary to take account of factors that determine what proportion of the (potential) travelling population will actually make use of such systems. Ultimately changes in travel choices depend upon the viability of the choices known to be available. As transport policymakers look to achieve a better distribution of travel across modes it is important to recognise that information provision alone cannot achieve this. Alternatives to travel by car must themselves be improved. If this can be achieved then information will have an increasingly important role in redressing ill-informed perceptions of cost. At the heart of effective information provision is the information itself. It is essential that such information matches the needs of users. 


\section{REFERENCES}

Alder, J.L. and Blue, V.J. (1998). Toward the design of intelligent traveler information systems. Transportation Research, 6C(3), 157-172.

Anderson T. (1993). Real-time passenger information for transit systems: proposals for the Jubilee Line Extension. Proc. $21^{\text {st }}$ PTRC Summer Annual Meeting, Public Transport Planning and Operations, University of Manchester Institute of Science and Technology, England, September, 153-173.

Austin, J. (1999). Towards comprehensive national public transport information on the Internet: the PTI Web site. Proc. AET European Transport Conference: Public Transport, Planning and Management, University of Cambridge, England, September, PTRC, 151-163.

Ben Akiva, M. and Lerman, S.R. (1993). Discrete Choice Analysis - Theory and Application to Travel Demand. Manheim, M. (ed.), MIT Press.

Brown, S. (1994). Implementation of a public transport information system in a deregulated environment. Proc. 22nd PTRC European Transport Forum, Public Transport Planning and Operations, University of Warwick, England, September, 49-59.

Brown, S. and Ness, M. (1995). The ROMANSE TRIPlanner. Proc. 23rd PTRC European Transport Forum, Public Transport Planning and Operations, University of Warwick, England, September, 61-72.

Confederation of British Industry (1995). Moving Forward - a Business Strategy for Transport.

Gillam, T., Lyons, G.D. and McDonald, M. (1999). Traveller information systems: what do end-users really want? Proc. AET European Transport Conference, Public Transport, Planning and Management, University of Cambridge, England, September, PTRC, 329-341.

Internet Magazine (1999). Trendspotting. Internet Magazine, Dec.

London Transport (1997). The Travel Information Service. Fact Sheet, Customer Service Centre, August.

Lyons, G.D. (2001). Toward integrated traveller information. forthcoming in Transport Reviews.

McDonald, M., Richards, A. and Shinakis, E.G. (1995). Integrated urban transport management in Southampton. Proc. 2nd World Congress on Intelligent Transport Systems, 1, Yokohama, November, 310-315.

McIntosh (2000). Handset sales near 50,000 a day as mobile phone fever grips UK. The Independent, Business Section, 6 January, 16.

Nuttall, I. (1995). RDS-TMC: Will Europe get it together? Traffic Technology International, Autumn, 3236.

Ortúzar, J. de D. and Willumsen, L.G. (1994). Modelling Transport. Wiley.

Wells, K. and Horan, T. (1999). Toward a consumer demand-driven intelligent transportation system policy: findings from Southern California. Transportation Research Record, 1679, 64-72. 